\title{
Experiences of Staying Healthy in Relationally Demanding Jobs: An Interpretative Phenomenological Study of Work-Engaged Nurses in the Hospital
}

\author{
Asgerdur Bjarnadottir*, Kjersti Vik \\ Faculty of Health and Social Work, Sør-Trøndelag University College, Trondheim, Norge \\ Email: ${ }^{*}$ Asgerdur.Bjarnadottir@hist.no
}

Received 16 April 2015; accepted 8 May 2015; published 11 May 2015

Copyright (C) 2015 by authors and Scientific Research Publishing Inc.

This work is licensed under the Creative Commons Attribution International License (CC BY). http://creativecommons.org/licenses/by/4.0/

c) (i) Open Access

\begin{abstract}
Background: Based on the experience of hospital nurses, the aim of this study is to explore the phenomenon of how work-engaged nurses stay healthy in relationally demanding jobs involving very sick and/or dying patients. Method: In-depth interviews were conducted with ten workengaged nurses employed at the main hospital in one region in Norway. The interviews were interpreted using the Interpretative Phenomenological Analysis method (IPA). Results: The results indicate the importance of using the personal resources: authenticity and a sense of humour for staying healthy. The nurses' authenticity, in the sense of having a strong sense of ownership towards their personal life experiences, and a sense of having a meaningful life in line with their own values and interests, was an important element when they considered their own health to be good in spite of repetitive strain injuries and perceived stress. These personal resources seem to be positively related to their well-being and work engagement, which serves as an argument for including them among other personal resources, often conceptualized in terms of Psychological Capital (PsyCap). The results also showed that the nurses worked actively and intentionally with conditions that could contribute to safeguarding their own health. Conclusion: The results indicated the importance of stimulating the nurses' area of knowledge about caring for themselves in order to enable them to maintain good physical and mental health. A focus on self-care should be part of the agenda as early as during nursing education.
\end{abstract}

\section{Keywords}

Health, Personal Resources, Work Engagement, Relationally Demanding Jobs, Nurses,

\footnotetext{
"Corresponding author.
}

How to cite this paper: Bjarnadottir, A. and Vik, K. (2015) Experiences of Staying Healthy in Relationally Demanding Jobs: An Interpretative Phenomenological Study of Work-Engaged Nurses in the Hospital. Open Journal of Nursing, 5, 437-450. 


\section{Interpretative Phenomenological Analysis}

\section{Introduction}

This paper focuses on the perceived experience of work-engaged nurses who work in relationally demanding jobs when it comes to staying healthy while caring for very ill and/or dying patients in the hospital. Nurses with an experience of life-and-death issues have traditionally been associated with a risk of stress, strain injuries and burnouts due to their exposure to frequent deaths and family grieving [1]. However, there is no strong evidence that hospital nurses in this kind of job experience a higher level of stress than nurses in other disciplines [1], and a study has shown that nurses maintain their engagement even after many years on the job [2].

Work engagement is in line with the perspective of "positive psychology", which concerns itself with the positive aspects of employee health and resources [3], and is defined by Schaufeli and his colleagues as: " $A$ positive, fulfilling, work-related state of mind that is characterised by vigour, dedication, and absorption" ([4], p. 74). Based on this definition, we have focused on vigour (having a high level of energy at work and being strongly motivated by his or her job) and dedication (being strongly involved in the job) [4].

In positive psychology, health is often related to psychological health and well-being rather than psychological suffering. Subjective well-being (SWB) is defined as a person's affective and cognitive evaluation of one's life, and the evaluation includes emotional reactions to events and cognitive judgment of fulfilment [5]. SWB encompasses one's perceptions and feelings of psychological, emotional and social well being [6]-[8]. In addition, physical well-being is also seen as an important part of health, as the nurse's job is also physically demanding, involving, for example, heavy lifting.

Quantitative studies have shown that work engagement is positively associated with employee health [9]. In general, engaged employees perceive themselves as having better physical health, less burnout and lower levels of anxiety and depression [10]-[12], and they often experience positive emotions, including satisfaction with their own life, as well as better psychological health [13]; however, the research on the status of self-perceived health is still limited.

Staying healthy with regard to engagement has to do with both personal resources and job resources [14]. According to one of the leading job stress models in psychology, Job Demands-Resources (JD-R) [15], there are two critical psychological processes that occur at the workplace that have different effects on employee wellbeing. The first is a health impairment process, which results from excessive job demands, such as overload, and can result in burnout and negative health outcomes [15]. The second is a motivational process, which follows from having access to adequate job resources, and more recently, personal resources, and achieving results through work engagement and positive work outcomes, such as high performance. According to the model, work engagement is a mediator between the job and personal resources and positive outcomes. The model assumes that work engagement occurs when resources are high and that any resources may thus affect employee health and well-being [14].

The JD-R model has been criticized for neglecting the role of employees' personal resources. As the early versions of the JD-R model consider only characteristics of the work environment, there are still several unresolved issues regarding the role and incorporation of personal resources in the JD-R model. Personal resources are defined as those aspects of the self that are generally associated with resilience. This refers to the ability to impact and control one's environment successfully [16], and has often been conceptualized as Psychological Capital (PsyCap) comprising resilience, self-efficacy, optimism and hope [17]. However, there are still other positive constructs that can meet the criteria of PsyCap, and it's not unlikely that the different types of jobs need different kinds of personal resources among the employees in order to stay healthy in their jobs.

In general, relatively few studies have examined the role of personal resources, but some studies have shown that personal resources directly impact work engagement and well-being. A study among teachers [18] found that emotional and mental competencies could predict levels of burnout and engagement, and a longitudinal study had shown that personal resources (self-esteem, self-efficacy and optimism) could predict later workengagement [19]. Studies have also shown that personal resources are associated with fewer stress symptoms [20], better mental health [21], and a recent study has also confirmed that the positive effect of personal resources on employee health holds over time [22]. 
To our knowledge, studies concerning experiences of work-engaged nurses in staying healthy are still limited, but some studies have shown that personal resources such as resilience [2], existential fulfilment [23], introspection and reflection [24], and experience of meaningfulness [2] [24] influence work engagement positively.

Basing itself on the self-perceived health status of hospital nurses, the aim of this study is to explore the experience of staying healthy in relationally demanding jobs while caring for very ill and/or dying patients. The focus of this study will be on personal resources.

\section{Method}

Data were collected through in-depth interviews [25], and an interpretative phenomenological analysis (IPA) [26] was used in the interpretation of the data. IPA has specifically been developed by Jonathan Smith to allow rigorous exploration of subjective experiences and social cognition [27].

The approach used in IPA is strongly influenced by phenomenology [28] in the sense that it involves a detailed examination of the participant's life-world and personal experiences. The IPA also recognizes the researcher's interpretation of the material. In the process of analysis, existing theories are taken into account [29]. The aim of IPA studies is to say something in detail about the understanding of this particular group, rather than making more general claims. IPA studies are conducted on small sample sizes [27].

\subsection{The Sample}

The data was collected at the main hospital in one region in Norway. First, a strategic selection of hospital departments was made [30] [31]. The inclusion criterion was that the nurses there must be working in a relationally demanding job, and three departments who treated patients with a direct experience of life-and-death issues fulfilled the criterion. The patients in the three departments represented all age groups, i.e., from young children to adults. An information leaflet was sent to the departments, and the respondents who perceived themselves to have work engagement and had worked in the same department for at least three years were encouraged to register as participants.

This study is based on the interviews with ten nurses who had strong self-reported work engagement. The nurses' work involved caring for patients who were seriously ill and/or dying. They were the primary contact nurses for a certain number of patients and their immediate families. The nurses' age ranged from 31 to 51 years. The nurses' working experience in their present department varied from 4 to 16 years. Eight participants worked full-time, whereas two were employed part-time. Nine of the respondents had participated in further training in the respective areas of their departments. The informants were either married or lived with a partner and had children and/or teenagers living at home.

\subsection{Data Collection}

The data was collected by the first author through semi-structured in-depth one-to-one interviews with openended questions. Each interview lasted for 1.5 to 2 hours. This form of interviewing allows for dialogue and enables the researcher to further explore important points that arise [27]. The first question of the interview was about work engagement (vigour and dedication) based on questions about work engagement from "The Utrecht Work Engagement Scale”. Examples of such questions are as follows: Do you think you have a meaningful job? Are you proud of the job you are doing? Does the job inspire you? The aim of these questions was to explore whether the participants really did have work engagement. The following topics were subsequently covered in the interviews: self-perceived health status, how they coped with work stress, their life values, motivation for choosing the nursing study programme, and the ability to care of oneself. The participants were encouraged to talk about these issues as freely as possible, and each interview lasted for 1.5 to 2 hours. All interviews were tape-recorded. At the completion of each interview, the first author listened to selected parts of the recording that could possibly require changing the interview guide. The aim was to pick issues that could contribute to shedding light on and improve the research question. The interview guide was subsequently subject to small adjustments and improvements. An example of this is when the nurses stated that it was invaluable to have a sense of humour to maintain good mental health. Questions about humour had not been included in the original interview guide. Finally, the interviews were transcribed verbatim. 


\subsection{Data Analysis}

The analysis was carried out according to Interpretative Phenomenological Analysis (IPA) [28]. The reason for using IPA as an analytical method was to create a better understanding of the experience of the hospital nurses in staying healthy in relationally demanding jobs.

The analysis was carried out in several steps, and examples of the analysis in the first theme "A positive sense of ownership towards personal life experience" are shown in Table 1.

1) The first author began by examining the transcript of one interview in detail before moving on to the other interviews. Each interview was then read through several times to gain a first understanding. Preliminary notes were prepared on the basis of preliminary theme, associations or questions.

2) The connection between the meaning units was examined, and some of the meaning units were clustered together. Key phrases capturing the essence of the informant's statements, such as "trying to develop my nursing skills", were used to identify concurrent topics, such as "developing one's potential".

3) Providing structure to the analysis to increase the understanding of the processes and structures emerging from the research material.

4) Further refining the themes by creating a summary to help divide the themes into main themes and subthemes. Theories, such as the JD-R model and PsyCap, were applied during steps three and four to increase the understanding of the processes and structures that emerged from the research material. This process is in line with IPA. Research is viewed as a dynamic process where the analysis represents an on-going process of interpretation by the researcher. The method is connected to a two-stage interpretation process or a double hermeneutic process [29]. Direct quotes from the interviews are presented in the text as quotations.

The results are evident in tree main themes and six sub-themes (in brackets) (see Table 2): Having a positive sense of ownership towards one's own life experiences (including the sub-themes: perceived health is a result of having lived one's life in the way one wants, being true to one's own values and personal interests, and developing one's potential), Being sensitive to their own needs in order to take care of their own health (including the sub-themes: setting limits, being physically active and having mutual social relations in general), and having a sense of humour.

\subsection{Validity}

The first author discussed the study, its method and findings, with colleagues from other professions in seminars and lectures. The purpose of this discussion was to obtain as much insight as possible.

\subsection{Ethical Considerations}

This study was approved by the Norwegian Social Science Data Service (NSD) and the Regional Committee for

Table 1. Example of structural analysis of the first topic: "Having a positive sense of ownership towards one’s own life experiences”.

\begin{tabular}{|c|c|c|c|}
\hline Meaning unit & $\begin{array}{l}\text { Connecting the meaning unit } \\
\text { into themes }\end{array}$ & Sub-themes & Main themes \\
\hline $\begin{array}{l}\text { “You know, I am kind of worn down here and } \\
\text { there, but you know, it’s a pretty natural thing } \\
\text { considering the job I have.” } \\
\text { "My job gives me a strong feeling of having a } \\
\text { meaningful life.” } \\
\text { "Considering my age, my health is pretty good.” }\end{array}$ & $\begin{array}{l}\text { Health is related to the feeling of } \\
\text { having a meaningful life, life } \\
\text { experiences and life stages. }\end{array}$ & $\begin{array}{c}\text { Perceived health is a result } \\
\text { of having lived one's life in } \\
\text { the way one wants }\end{array}$ & $\begin{array}{l}\text { Having a positive } \\
\text { sense of ownership } \\
\text { towards one's own } \\
\text { life experiences }\end{array}$ \\
\hline $\begin{array}{l}\text { "I am both caring and conscientious. It is } \\
\text { important to be these things when choosing } \\
\text { the nursing profession." } \\
\text { "I have always wanted to have more children, } \\
\text { which I have indeed gotten.” }\end{array}$ & $\begin{array}{c}\text { Making choices in life is related to } \\
\text { personal values and interests }\end{array}$ & $\begin{array}{l}\text { Being true to one's own } \\
\text { values and personal } \\
\text { interests }\end{array}$ & \\
\hline $\begin{array}{l}\text { "I try to stay updated in my field as far as possible, } \\
\text { and attend seminars when I feel that I should." } \\
\text { "I want to get things done and get them resolved, } \\
\text { so I check with the others when I cannot find } \\
\text { the answer myself." }\end{array}$ & $\begin{array}{l}\text { Utilizing available opportunities } \\
\text { in order to develop themselves in } \\
\text { their professional practice }\end{array}$ & Developing one’s potential & \\
\hline
\end{tabular}


Table 2. Summary of findings on staying healthy in relationally demanding jobs.

\begin{tabular}{ccc}
\hline $\begin{array}{c}\text { Having a positive sense of ownership } \\
\text { towards one's own life experiences }\end{array}$ & $\begin{array}{c}\text { Being sensitive to their own needs } \\
\text { in order to take care of their own health }\end{array}$ & Having a sense of humour \\
\hline $\begin{array}{c}\text { Perceived health is a result of having lived one's } \\
\text { live in the way one wants }\end{array}$ & Setting limits \\
$\begin{array}{c}\text { Being true to one's own values and personal } \\
\text { interests }\end{array}$ & Being physically active \\
Developing one's potential & Having mutual social relations in general
\end{tabular}

Medical and Health Research Ethics (REK) of mid-Norway. Participants were informed that participation was voluntary and that their confidentiality would be respected.

\section{Results}

\subsection{Having a Positive Sense of Ownership towards One's Own Life Experiences}

Staying healthy involved having a positive sense of ownership towards one's own life experiences, and included: Perceived health is a result of having lived one's life in the way one wants, being true to one's own values and personal interests, and developing one's potential.

\subsubsection{Perceived Health Is a Result of Having Lived One's Life in the Way One Wants}

Paradoxically, all the nurses considered their own health to be good, in spite of various health ailments such as high blood pressure, stress and insomnia: "My health is impeccable. Fortunately, it is impeccable".

The nurses considered their health to be a result of the life they lived and had chosen to live. They respected themselves as authorities of their own lives and accepted the consequences of their own choices. One nurse said, "I have wanted to be a nurse for as long as I can remember, but it is a stressful profession which takes its toll on one's health. However, I knew that from the beginning.” They expressed how a lengthy professional practice in such a demanding job had contributed to strains in the skeleton and muscles. Repeated heavy lifting and working in difficult positions in cramped patients' rooms had caused both inflammation and minor damages to the neck, shoulders and back area. Five of the respondents suffered from various health ailments related to strain injuries. One nurse said, "You know, I am kind of worn down here and there, but you know, it's a pretty natural thing considering the job I have."

The strain injuries they had incurred affected their health, and all five nurses received treatment at regular intervals in order to repair and prevent physical strain and injuries. "I am seeing a manual therapist every fortnight that takes care of the chronic shoulder inflammation" and "I go to a physical therapist once a week for a dose of maintenance in relation to a shoulder inflammation.” The nurses communicated that the treatment had good results, which meant that they did not have to be absent from work. In addition to work related strain injuries, they also suffered from various ailments that affected their daily lives. One nurse said, "My blood pressure is a little high, and so is my cholesterol and so on, and then I got a minor back injury at work a few years back, but all in all I'm in good health."

Making choices according to their own personal interests also made it natural for them to accept the conesquences of the choices they had made. The other five informants had preschool children, and they found it to be quite natural for this stage of their lives to be hectic. One nurse said, "You know, I think of it like this: NOW I'm in a phase where I have kids - we have made the choice to have kids ourselves, and so we should accept the consequences thereof. No use complaining-you can't change it anyway. I have chosen to work full-time, so that's a choice I have made".

All of them suffered from bouts of insomnia, as well as stress during hectic periods of their working day, but that was explained as being a natural part of living life with small children. They made statements as follows:

"I am mostly healthy; I've been lucky there. I have some troubles sleeping occasionally, but I guess that's a pretty normal part of having small kids." and "It's rather hectic at times, and I often feel stressed, but I guess that's part of the job. My health is excellent, and I am rarely ill”. They also expressed that they were frequently busy, but this did not bother them in their daily lives. All of the nurses expressed that they were usually physically tired after work, but they found it to be quite natural when considering the hectic life at the different units. 


\subsubsection{Being True to One's Own Values and Personal Interests}

The nurses made choices in line with their own values and interests, and they had a positive view of their own experiences. From an early age, they had wanted to become nurses and finished the nursing education while they were relatively young. They were positive towards providing care for others, and they had positive associations towards value-laden terms that are related to providing care, such as being conscientious, scrupulous and assuming responsibility. This is borne out as,

"I am very conscientious; I am not able to let other people be negatively affected. And I am very scrupulous. Well, I may seem to toot my own horn quite a bit here, but I have actually received very positive feedback on these things."

The nurses found an almost existential purpose with their jobs, and said it was inherently meaningful to be able to contribute to helping people who were in deep distress, and they channelled their own values through their work performance. One nurse said, "I have a unique job that I am very happy with. To me, it is meaningful to be able to contribute to helping patients in the situation they are in. It gives me a strong sense of living a meaningful life."

The informants expressed that their job had affected them as persons, making them feel less peremptory, more liberal, and less judgmental. They said, "When you work with the things I'm working with here—and when they no longer affect you - the day I am no longer being affected by my job, that's when I think I'll stop working there, really." The job has also influenced the personal values of some of them in the sense of making them less materialistic: "I also find that much of the stuff that I see other people using their time and energy on, such as interior decoration, we spend no time on that in our home. It is pretty irrelevant if the curtains are red or blue." They also expressed that experiences from work had contributed to making them more present in the moment. Their experiences had taught them that there is a thin line between life and death, and that it was important to be present in the moment instead of living in the future. One nurse said, "I'm not one of those who worries about the future. What's the point of that?"

The results also indicated that they were satisfied with their own personal lives and made conscious choices based on their own interests. "I can't be bothered to go around being annoyed by trifles-I don't want to waste my energy on the fact that it is raining. I have always wanted my own family, and now I have one. What more could I want? I like it just the way it is." Another nurse stated, "I am pleased with the life I am living."

\subsubsection{Developing One's Potential}

The final dimension linked to having a positive sense of ownership towards their own life experiences was connected to developing one's own potential. The nurses expressed having a positive relationship towards their own personal development and that they were in a steady process of personal and professional development. Nine of the ten nurses had undergone further training in their field of expertise, and they attended courses that were relevant to their field. One nurse said, "I try to stay updated in my field as far as possible, and attend seminars when I feel that I should.” They accepted themselves just the way they were, and were realistic when it came to their own abilities. One nurse said, "I must accept that I do not know EVERYTHING. I am good at some things, less good at other things.” They seemed to be very solution-oriented, and they tried to resolve unsolved problems as soon as possible so they would not wear them down. One nurse said, "I want to get things done and get them resolved, so I check with the others when I cannot find the answer myself."

To develop their own potential, the nurses processed and reflected on difficult experiences either by reflecting on them on their own, or seeking assistance when they needed help to move on. They learned from the ways in which they dealt with issues and accepted their own inadequacy in certain situations. One nurse said, "It is important to accept that I could not have done anything differently then and there."

All the nurses expressed how they had mostly been regarded as positive persons. They tried to make the best of the situation they were in by focussing on the opportunities rather than the deficiencies. One nurse said, "It is important to concentrate on the things you can do something about. Get to grips with it and make the best out of it." Another nurse said, "I get many questions about how it is possible to work in a place like this. To me, it's not so much about death. It's rather about making life as good as possible for those who are here.” They also focused on the healthy part of the patient, rather than the part suffering from illness: "We are very concerned with highlighting the healthy parts of the human being." But at the same time, they are realistic: "It is the healthy part we use our time and energy on at work, but it has to be a realistic optimism taking the person's diagnosis into account.” In focussing on the healthy aspects of the patients, the nurses contributed to developing 
positive relations with the patients.

\subsection{Being Sensitive to Their Own Needs in Order to Take Care of Their Own Health}

Staying healthy means being sensitive to their own needs, including setting limits, being physically active, and having mutual social relations in general.

\subsubsection{Setting Limits}

The respondents perceived themselves as having a good knowledge of their own physical and mental health, and they were sensitive toward their own needs in almost all situations. One dimension of being sensitive toward their own needs was setting limits. Their ability in setting limits was expressed as a sense of knowing their own personal limits. They accepted their own limitations, and they sought help when they needed it. The nurses' long professional experience was a factor that reduced having them bring work-related problems home, and vice versa, thinking about domestic issues when they were at work. They felt a strong sense of work engagement, which they regarded as a prerequisite to be able to deal with their job. However, their work engagement was mostly limited to the job arena.

They also believed that it was important to be highly mentally balanced in order to do a good job, and they stayed at home when they experienced great personal stress. One nurse said, "I believe it is impossible to combine such a tough job with personal stress. When I lost my sister five years ago, I was absent for several weeks after the funeral in order to recover.” They also chose to stay at home when they were ill or in poor shape, and they believed the department could manage well without them. One nurse said, "If I had a fever or a headache, I would stay a day or two in bed and know that the world moves on just fine.” Moreover, the informants enjoyed spending time on their own, without having to do anything in particular. As one of the mothers with young children said, ".. and just having some time to oneself after the children are in bed, and not doing anything, it's delightful." Another said, "When I need it, I like to lie on the couch with a good book, watch TV or reflect on life in general."

\subsubsection{Being Physically Active}

Another dimension of being sensitive to their own needs was related to physical activity. The nurses felt that physical activity was energising, and they were eager to try to keep in shape. Most of the nurses were physically active in some form or another, and they felt that they had good physical health. They were often physically tired after work and felt that a workout restored their energy. Six of them exercised regularly, up to several times a week either at the gym or by jogging, walking or cycling outside. Some of the nurses were physically active in several ways. One nurse said, "I do weight training, go cross-country skiing, run, walk in the woods, cycle and walk in the mountains." The other four respondents had children under school age or in primary school, and they adapted their activities to their children's needs. They prioritised the follow-up of the children's activities in everyday life, and their afternoons were often busy and involved driving the children to different activities, but they were often physically active together with the family on weekends. One nurse said, "I walk and swim together with the children or we go for walks together. On weekends we often go walking in the woods. It's a great way to relax.”

\subsubsection{Having Mutual Social Relations in General}

The last dimension relating to being sensitive toward their own needs concerned social relations in general. The nurses valued social interaction highly, and they believed there was a curative effect in being in the company of others. They maintained relationships with family and friends in an outreaching and active manner by, among other things, inviting them home from time to time. One nurse said, "I am very social, I enjoy good company, and I often invite others to dinner.” However, they also expressed that the relationships were reciprocal, that they had both a private network as well as a work network with colleagues who were a great support for them whenever they needed it, and that their spouses often held a unique position in this context.

\subsection{Having a Sense of Humour}

All the nurses thought it was invaluable to have a sense of humour in order to maintain good health. They worked with very serious problems in heart-rending human conditions, and they often had to deal with patients 
and their families who were in despair. They found it necessary to have a sense of humour to distance themselves from exceedingly difficult situations. One nurse said, "It is important to have a counterpoint to the seriousness of it all—we must get some humour into the department." Another nurse said, "We work with patients who have a really tough time, and their relatives, who are in a state of crisis when they lose their loved ones. It's a tough job, and it is absolutely necessary to have a sense of humour around here.” Meeting colleagues in the staff room was often used as a relief station when the pressure became too high in the departments.

Four respondents claimed that they did not have a good sense of humour when they began working in the departments, but they had learned from their colleagues and eventually became integrated into the department's internal humour. The various departments had developed a certain kind of gallows humour, which was internal and unique to the department. One nurse said, "The jokes, the irony and the gallows humour that we have in the staff room should not be heard outside the door, one has to be aware of the surroundings in order to cope and understand that it is actually all right and not meant in a negative manner. We have a lot of humour in the departments." The nurses also used humour in conversations with the individual patients, but they stressed that they were careful in their speech, and wanted to get to know the patients before they used this form for communication. One nurse said, "It is possible to be witty about it, even though everyone knows that at the end of the day it is a tragic case." The nurses believed that a good laugh relieved the physical and psychological pressure that could occur in difficult situations, and it made them relax and focus on the positive aspects of the situation.

\subsection{Summary of the Results}

Interestingly, the summary of the results shows that the nurses considered their health to be good in spite of having various ailments in the form of strain injuries, stress, insomnia and high blood pressure. How is it possible to feel that one are in good health when one is suffering from such ailments? The results indicate that the nurses had a positive sense of ownership towards their own life experiences, and they perceived their health status to be a natural consequence of the life they were living and had lived. They lived a life that was in line with their values and interests, and their sense of having a meaningful life had a significant effect on their ability to stay healthy. They had a pragmatic approach towards their own health, regarding health as a relative phenomenon that had to be considered in relation to what they found reasonable to expect in terms of life stages and life experiences. They took it for granted that life experiences left their marks on them, and they would suffer a little from ailments and strain after spending years in such a strenuous job.

The nurses viewed life as something that could be affected, and they considered themselves to be fully able to influence their own health in a favourable manner. They were sensitive toward their own needs, and the results show that the nurses' experiences imply that it was important to address both their physical and mental health. They were actively coping with regard to choosing activities that were right for them and gave them energy.

All the nurses also emphasized the importance of having a sense of humour related to the job in order to maintain good health.

\section{Discussion}

The aim of this study was to explore work-engaged nurses experiences of staying healthy in relationally demanding jobs involving caring for very ill and/or dying patients. The focal point of this study has been personal resources. Findings in the present study give new insights into the nurses' use of personal resources and also provide new insights in the nurses' self-perceived health. First, the findings pertaining to the authenticity of personal resources and sense of humour will be discussed. These are two new personal resources that have to do with work engagement and staying healthy that have, as far as we know, not been identified in previous studies, and hence, they will be given special attention in the discussion. The findings will then be discussed in terms of extending the scope of PsyCap, as well as possible implementation in the JD-R model.

The results showed that the nurses were pleased with their own situation, and they had a strong sense of ownership towards their own life experiences. Their feeling of leaving a meaningful life, which was in line with their values and interests, was a significant factor when they assessed their own health. The nurses made choices in line with their own values, accepting that the consequences of the choices they made came naturally to them. Educating themselves to be nurses was one of the important value choices they had made, and they channelled their abilities through their professional practice. They were also satisfied with their own personal lives and said they had each gotten the family they had wanted. 
The results may indicate that the nurses had a great degree of authenticity in their personal resources, which is termed in positive psychology as a higher-order strength or capacity [17]. Authenticity is a matter of staying true to oneself and acting in accordance with the true self, expressing oneself in ways that are consistent with the inner feelings and thoughts, as defined in positive psychology [32]. A "great degree" of authenticity involves the fact that a person rarely has one genuine authenticity, but possesses multiple selves: some actual and some possible [33]. The dominating approach towards authenticity is to understand autonomous acts as being authentic acts; that is, the action springs from values, wishes or motivations which the persons identify with [32]. Several studies have shown that the consequence of not identifying with an activity, or not feeling competent to perform it, may have contributed to the symptoms of burnout and problems in maintaining their health over time [34][36]. When the nurses act in accordance with their own values and interests, they can avoid feeling the stress that is often connected with acts of inauthenticity and thus gain positive health benefits. This results is in line with a study among nurses who work in palliative care that showed that authenticity is one of the most important characteristic of professionals [37], and also other studies that emphasized authenticity among nurses to be an important characteristic of professionals in their practice in dealing with patients in various critical conditions [38] [39]. As we mentioned earlier, authenticity in terms of higher-order strengths or capacities has, to our knowledge, not been identified as a personal resource in previous studies dealing with work engagement and staying healthy. This may, for example, be as a result of the choice of method the study employs. Most of the studies that have looked into personal resources are quantitative [18]-[21] where specific personal resources are tested, which may limit the amount of findings. This study, however, was conducted using in-depth interviews where the nurses were encouraged to talk as freely as possible about their experiences when it came to staying healthy, which may have contributed to allowing greater access to information that yield a more comprehensive image of their experiences.

In order to enhance their authenticity, people have to employ self-development and self-regulation [33], and the results showed that the nurses were in a constant process of professional and personal development. Nine of the ten nurses had undergone additional training within their professional field, and they also attended classes that were relevant to their work. The nurses also processed problematic experiences by either reflecting on them on their own, or by seeking assistance when they needed help to move on. Dealing with life-and-death issues relating to patients involves gaining intimate knowledge of the frequently tragic stories of patients and their loved ones. In order not to lose faith in their own professional practice, processing problematic work experiences may have a great impact on the health of the nurses. This result is in line with several established theories, including a subjective well-being (SWB) [5], self-determination theory (SDT) [40] [41], theory of self-efficacy [42], and Antonovsky's theory on the sense of coherence [43], which stresses the importance of personal development and confidence in one's own abilities in order to perceive oneself as having good mental health. This is also in line with studies among nurses who point to the traits mentioned above as being important in order to maintain a good health [44] [45].

Authenticity also includes being true to one's own needs and wants [17], and the results showed that the nurses were sensitive to their own needs. Their experiences imply that it was important to address both their physical and mental health, and they considered themselves to be fully able to influence their own health in a favourable direction. In order to safeguard their health, they used active coping in terms of choosing activities that were right for them and gave them energy. The nurses chose activities and developed relationships that they believed were of significant importance in relation to maintaining one's health.

The nurses prioritised their own interests, and they chose to stay at home when they were ill or in poor shape, a choice that helped them protect their physical health against further stress. Furthermore, they were aware of processing the emotional stress that occurred at, e.g., a death in the immediate family, and they chose to be absent from work in such instances. In an exposed occupation that requires both emotional and physical strength, it may be of crucial importance for the safeguarding of one's health that the nurses are well when they are at work; otherwise, the wear and tear will, in time, be too great. The informants were also concerned with trying to keep fit, and they found that physical activity restored their energy after work and contributed to maintaining good health and preventing repetitive strain injuries. This result is in line with studies showing that physical exercise and physical resources have positive health effects [46]. One study has also suggested that possible pathways linking physical activity with improved physical health could lead to reduced levels of inflammatory processes in the body [47].

The result is in line with Antonovsky's theory SOC [48], which focuses on people's view of life and their 
abilities to assess and understand the situation they find themselves in, finding meaning in moving in a direction that promotes health. Furthermore, the result is in accordance with Bandura's theory of self-efficacy, which involves the belief in one's own ability to organise and take actions that are necessary to maintain certain benefits [49]. In addition, research has shown that nurses who take care of their own health have a better sense of wellbeing [44] [45], and in a recent study among work-engaged nurses in Uganda [44], the results showed that the nurses used coping strategies like introspection, sharing of experiences, engaging in enjoyable activities, and taking care of their own health.

The analysis also revealed another personal resource among the nurses: having a sense of humour. The nurses thought it was invaluable to have a sense of humour in order to maintain good mental health at work. When being involved with very sick and/or dying patients, some situations require for one to be able to distance oneself from the situation. The nurses felt that a good laugh relieved the physical and psychological pressure that could build up in difficult situations and gave them the energy to focus on the positive aspects of the situation. This is in accordance with studies that show that humour has been associated with a positive coping style and is considered one of the positive defence mechanisms people need in order to cope with the stresses of everyday life [50]. Studies have also shown that humour can reduce the risk of health problems such as muscular pain and digestive problems [51], and a friendly sense of humour improves our physical and mental health: it strengthens the immune system and makes our skeletal muscles relax [52]. Furthermore, the results showed that the nurses developed a sense of humour in line with the internal humour in their respective departments. This suggests that it is possible to learn and develop humour, and this finding is in line with recent research that suggests humour is developed and altered through observations, imitations, and cognitive restructuring [52].

The above-mentioned results indicate that both authenticity and a sense of humour are personal resources that are of great importance for the nurses when it comes to staying healthy; however, these personal resources are still not included in PsyCap. As mentioned earlier, personal resources are defined as aspects of the self that are generally associated with resilience [16], and have often been conceptualized as Psychological Capital (PsyCap) comprising resilience, self-efficacy, optimism and hope [17]. PsyCap inclusion criteria include personal resources that are positive constructs, theory based, trait like/relatively fixed, state like/malleable, related to work performance and other positive outcomes [17]. As the results show, authenticity and humour fulfil all these criteria. They are personal positive resources that can be developed in line with current and future challenges, and that contribute to self-development and growth. Thus, the findings indicate that both authenticity and humour as a personal resources could have been included in PsyCap.

Paradoxically, the results showed that the nurses perceived themselves as being in good health, in spite of a number of ailments stemming from repeated strain or stress.

The results are in line with SWB, which is defined as a person's affective and cognitive evaluation of one's own life, as well as the fact that the evaluations include emotional reactions to events and cognitive judgment of fulfilment [5]. The results are also in line with a study which claimed that engaged employees often experience positive emotions, including satisfaction with one's own life [13], but the results are not in line with the studies that claim that work-engaged employees have better physical health than others [10]-[12]. So why do the nurses perceive themselves to be of good health despite suffering from a number of ailments caused by prolonged strain at work? There may be several reasons for this. Working with terminally ill patients may possibly make the nurses change their view on the importance of being of good physical health. If they compare their own health problems to those of their patients, theirs may seem to be relatively insignificant compared to those of their patients. A different, but possibly more likely, explanation may be that the nurses' authenticity determines the way they perceive their own health. The nurses considered health to be a relative phenomenon that had to be assessed against the backdrop of living the life they want and the life they had been living. They had wished to become nurses from an early age, and they took it for granted that their working experience would leave marks; they would suffer a little bit from ailments and wear and tear over the years in such a straining profession. This is in line with Social Cognitive Theory [49], which proposes that personal resources shape the way people understand their environment and react to it.

The JD-R model has been criticized for neglecting the role of employees' personal resources, and most of the studies among nurses have focused on job resources that predicted work engagement. For example, a supportive practice environment [2] [24] and job control [2] have been linked to the nurses' engagement. In this way, the work engagement becomes externally controlled and becomes the outcome of the balance between demands and resources. This relegates the typical characteristic of the profession, the dedication of nurses [53], to be some- 
thing that others can control, but the results from the current study indicate that personal resources such as authenticity and humour also are of great importance for the nurses' experience of trying to stay healthy. The results also indicate that the nurses' authenticity may shape the way they understand their own health and react to it, which indicates that personal resources may be a key factor for their perception of well-being and work engagement. The nurses' authenticity may explain why they still have a strong work engagement in spite of work-related strains. When they act in accordance with their own values and interests, they may avoid feeling stress that is often connected with inauthentic acts, thereby gaining positive health benefits in the form of engagement and well-being. The results also show that the JD-R model should focus more closely on profession characteristics. Staying healthy and work-engaged in a job involving very ill and/or dying patients possibly requires other personal resources than when one works as, for example, a school teacher. The nurses have to deal with existential questions about life and death nearly every day, a job characteristic that is special to their profession. The JD-R model is flexible and should thus include both professional and personal resources in a variety of work settings.

\section{Study Limitations}

This study has some limitations. The interviews were retrospective, and one cannot say whether the nurses' authenticity and sense of humour were an outcome of a long professional career, or whether they had these personal resources when they started working. Therefore, there is a need for longitudinal studies that can address the development of authenticity and sense of humour over time. The survey was conducted in only three departments in a medium-sized hospital, and it is therefore difficult to generalise the results to apply to workplaces other than departments at other hospitals that involve relationally demanding work. However, the study identifies personal resources and a way of safeguarding one's health that could potentially be linked to experiences of staying healthy over time in relationally demanding jobs.

\section{Conclusions and Practical Implications}

The results indicate the importance of using the personal resources authenticity and a sense of humour in the experience of staying healthy in the nurses' job, which involves very sick and/or dying patients. In hospital departments, a practice should be developed that encourages discussions and awareness of authenticity and a sense of humour, and the nurses' individual abilities and knowledge of the importance of caring for their own health in order to maintain good physical and mental health should also be encouraged. The nearest head of department can undertake the role to initiate such discussions. Furthermore, the results suggest that it might be appropriate to integrate physical training during working hours. This can be done by allowing each employee a one-hour workout session per week, which can take place at the end of the working day. An organised training program at the hospital's premises will encourage a sense of fellowship among the employees with regard to keeping in shape.

The personal resources authenticity and a sense of humour seem to be positively related to work engagement and well-being, serving as an argument to include them among other personal resources that has often been conceptualized as Psychological Capital (PsyCap). These results also serve as an argument for having personal resources included directly in the JD-R model on par with job resources, and also that job characteristics are significant with regard to how the employees utilize their personal resources.

These insights can possibly increase our knowledge on how nurses can improve their health. The current study revealed the need for studies focussing on personal resources in a variety of work settings.

\section{Competing Interests}

The authors declare that they have no competing interests.

\section{Authors' Contributions}

ABB drafted the introduction, carried out the design of the study, collected data, performed the analysis and drafted the methods and results. ABB and KV discussed the results of the data analysis, and ABB drafted the discussion section. KV served as an active discussion partner during the writing of the paper, and all the authors read and approved the final manuscript. 


\section{Acknowledgements}

The authors would like to thank the nurses for their generous participation in this study, and Sør-Trøndelag University College in Norway for their financial support.

\section{References}

[1] Peters, L., et al. (2012) Is Work Stress in Palliative Care Nurses a Cause for Concern? A Literature Review. International Journal of Palliative Nursing, 18, 561-567. http://dx.doi.org/10.12968/ijpn.2012.18.11.561

[2] Bjarnadottir, A. (2011) Work Engagement among Nurses in Relationally Demanding Jobs in the Hospital Sector. Vård i Norden, 31, 30-34. http://dx.doi.org/10.1177/010740831103100307

[3] Seligman, M.E. and Csikszentmihalyi, M. (2000) Positive Psychology: An Introduction. American Psychologist, 55, 5-14. http://dx.doi.org/10.1037/0003-066X.55.1.5

[4] Schaufeli, W.B., et al. (2002) The Measurement of Engagement and Burnout: A Two Sample Confirmatory Factor Analytic Approach. Journal of Happiness Studies, 3, 71-92. http://dx.doi.org/10.1023/A:1015630930326

[5] Diener, E., Oishi, S. and Lucas, R.E. (2009) Subjective Well-Being: The Science of Happiness and Life Satisfaction, in Oxford Handbook of Positive Psychology. Oxford University Press, New York, 187-194.

http://dx.doi.org/10.1093/oxfordhb/9780195187243.013.0017

[6] Keyes, C.L.M. (1998) Social Well-Being. Social Psychology Quarterly, 61, 121-140. http://dx.doi.org/10.2307/2787065

[7] Ryff, C.D. (1989) Beyond Ponce de Leon and Life Satisfaction: New Directions in Quest of Successful Ageing. International Journal of Behavioral Development, 12, 35-55. http://dx.doi.org/10.1177/016502548901200102

[8] Ryff, C.D. (2012) Existential Well-Being and Health, in the Human Quest for Meaning: Theories, Research, and Applications. Routledge/Taylor \& Francis Group, New York, 233-247.

[9] Llorens, S., et al. (2007) Does a Positive Gain Spiral of Resources, Efficacy Beliefs and Engagement Exist? Computers in Human Behavior, 23, 825-841. http://dx.doi.org/10.1016/j.chb.2004.11.012

[10] Hakanen, J.J., Bakker, A.B. and Schaufeli, W.B. (2006) Burnout and Work Engagement among Teachers. Journal of School Psychology, 43, 495-513. http://dx.doi.org/10.1016/j.jsp.2005.11.001

[11] Hallberg, U.E. and Schaufeli, W.B. (2006) "Same Same” but Different? Can Work Engagement Be Discriminated from Job Involvement and Organizational Commitment? European Psychologist, 11, 119-127.

http://dx.doi.org/10.1027/1016-9040.11.2.119

[12] Innstrand, S.T., Langballe, E.M. and Falkum, E. (2012) A Longitudinal Study of the Relationship between Work Engagement and Symptoms of Anxiety and Depression. Stress and Health: Journal of the International Society for the Investigation of Stress, 28, 1-10. http://dx.doi.org/10.1002/smi.1395

[13] Bakker, A.B., Schaufeli, W.B., Leiter, M.P. and Taris, T.W. (2008) Work Engagement: An Emerging Concept in Occupational Health Psychology. Work \& Stress, 22, 187-200. http://dx.doi.org/10.1080/02678370802393649

[14] Schaufeli, W.B. and Taris, T. (2013) The Job Demands-Resources Model: A Critical Review. Gedrag \& Organisatie, 26, 182-204.

[15] Bakker, A.B. and Demerouti, E. (2007) The Job Demands-Resources Model: State of the Art. Journal of Managerial Psychology, 22, 309-328. http://dx.doi.org/10.1108/02683940710733115

[16] Hobfoll, S.E., Johnson, R.J., Ennis, N. and Jackson, A.P. (2003) Resource Loss, Resource Gain, and Emotional Outcomes among Inner City Women. Journal of Personality and Social Psychology, 84, 632-643. http://dx.doi.org/10.1037/0022-3514.84.3.632

[17] Luthans, F., Youssef, C.M. and Avolio, B.J. (2006) Psychological Capital: Developing the Human Competitive Edge. Oxford University Press, Oxford.

[18] Lorente Prieto, L., Salanova Soria, M., Martínez Martínez, I. and Schaufeli, W. (2008) Extension of the Job DemandsResources Model in the Prediction of Burnout and Engagement among Teachers over Time. Psicothema, 20, 354-360.

[19] Xanthopoulou, D., Bakker, A.B., Demerouti, E. and Schaufeli, W.B. (2009) Work Engagement and Financial Returns: A Diary Study on the Role of Job and Personal Resources. Journal of Occupational and Organizational Psychology, 82, 183-200. http://dx.doi.org/10.1348/096317908X285633

[20] Avey, J.B., Luthans, F. and Jensen, S.M. (2009) Psychological Capital: A Positive Resource for Combating Employee Stress and Turnover. Human Resource Management, 48, 677-693. http://dx.doi.org/10.1002/hrm.20294

[21] Reis, D., Hoppe, A. and Schröder, A. (2015) Reciprocal Relationships between Resources, Work and Study Engagement, and Mental Health: Evidence for Gain Cycles. European Journal of Work and Organizational Psychology, 24, 
59-75. http://dx.doi.org/10.1080/1359432X.2013.834891

[22] Avey, J.B., Luthans, F., Smith, R.M. and Palmer, N.F. (2010) Impact of Positive Psychological Capital on Employee Well-Being over Time. Journal of Occupational Health Psychology, 15, 17-28. http://dx.doi.org/10.1037/a0016998

[23] Tomic, M. and Tomic, E. (2011) Existential Fulfillment, Workload and Work Engagement among Nurses. Journal of Research in Nursing, 16, 468-479. http://dx.doi.org/10.1177/1744987110383353

[24] Vinje, H.F. and Mittelmark, M.B. (2006) Deflecting the Path to Burn-Out among Community Health Nurses: How the Effective Practice of Self-Tuning Renews Job Engagement. International Journal of Mental Health Promotion, 8, 3647. http://dx.doi.org/10.1080/14623730.2006.9721750

[25] Denzin, N.K. and Lincoln, Y.S. (2000) Handbook of Qualitative Research. Sage, Thousand Oaks.

[26] Smith, J.A. and Osborn, M. (2008) Interpretative Phenomenological Analysis. In: Smith, J.A., Ed., Qualitative Psychology: A Practical Guide to Research Methods, 2nd Edition, Sage, London.

[27] Smith, J.A. and Osborn, M. (2008) Interpretative Phenemenological Analysis. In: Smith, J.A., Ed., Qualitative Psychology: A Practical Guide to Research Methods, Sage, London, 53-80. http://dx.doi.org/10.1002/9780470776278.ch10

[28] Smith, J.A. and Osborn, M. (2004) Interpretative Phenomenological Analysis. In: Breakwell, G.M., Ed., Doing Social Psychology Research, Blackwell Publishing, Malden, 229-254.

[29] Smith, J.A. and Dunworth, F. (2003) Qualitative Methodology. In: Valsiner, J., Ed., Handbook of Development Psychology, Sage, London, 603-621.

[30] Kvale, S. (1996) Interviews: An Introduction to Qualitative Research Interviewing. Sage, Thousand Oaks.

[31] Patton, M.Q. (2002) Qualitative Research \& Evaluation Methods. 3rd Edition, Sage Publications, Thousand Oaks, 427 S.

[32] Harter, S. (2002) Authenticity. In: Snyder, C.R. and Lopez, S.J., Eds., Handbook of Positive Psychology, Oxford University Press, New York, 382-394.

[33] Avolio, B.J. and Walumbwa, F.O. (2006) Authentic Leadership: Moving HR Leaders to a Higher Level. In: Martocchio, J., Ed., Research in Personnel and Human Resources Management, Vol. 25, Elsevier Science/JAI Press, New York, 273-304.

[34] Bjarnadottir, A. and Lillefjell, M. (2015) Critical Factors in Managing Relationally Demanding Jobs, in Care for Very Ill and/or Dying Patients: A Phenomenological Study among Public Hospital Nurses. Open Journal of Nursing, 5, 5867. http://dx.doi.org/10.4236/ojn.2015.51007

[35] Ryan, R.M. and Deci, E.L. (2000) Self-Determination Theory and the Facilitation of Intrinsic Motivation, Social Development, and Well-Being. American Psychologist, 55, 68-78. http://dx.doi.org/10.1037/0003-066X.55.1.68

[36] Ryan, R.M. and Deci, E.L. (2000) Intrinsic and Extrinsic Motivations: Classic Definitions and New Directions. Contemporary Educational Psychology, 25, 54-67. http://dx.doi.org/10.1006/ceps.1999.1020

[37] Simon, S.T., Ramsenthaler, C., Bausewein, C., Krischke, N. and Geiss, G. (2009) Core Attitudes of Professionals in Palliative Care: A Qualitative Study. International Journal of Palliative Nursing, 15, 405-411. http://dx.doi.org/10.12968/ijpn.2009.15.8.43800

[38] Holm, A.L. and Severinsson, E. (2011) A Hermeneutic Approach to the Characteristics of Mental Health Nursing Practice. Journal of Psychiatric and Mental Health Nursing, 18, 843-850. http://dx.doi.org/10.1111/j.1365-2850.2011.01736.x

[39] Seno, V.L. (2010) Being-With Dying: Authenticity in End-of-Life Encounters. American Journal of Hospice and Palliative Medicine, 27, 377-386. http://dx.doi.org/10.1177/1049909109359628

[40] Deci, E.L. and Ryan, R.M. (1985) Intrinsic Motivation and Self-Determination in Human Behavior: Perspectives in Social Psychology. Plenum, New York. http://dx.doi.org/10.1007/978-1-4899-2271-7

[41] Deci, E.L. and Ryan, R.M. (2000) The "What” and "Why” of Goal Pursuits: Human Needs and the Self-Determination of Behavior. Psychological Inquiry, 11, 227-268. http://dx.doi.org/10.1207/S15327965PLI1104_01

[42] Maddux, J.E. (2009) Self-Efficacy: The Power of Believing You Can. In: Lopez, S.J. and Snyder, C.R., Eds., Oxford Handbook of Positive Psychology, Oxford University Press, New York, 335-343.

[43] Antonovsky, A. and Lev, A. (2000) Helbredets mysterium: At tåle stress og forblive rask. Hans Reitzels Forlag, København, $231 \mathrm{~s}$.

[44] Bakibinga, P., Vinje, H.F. and Mittelmark, M.B. (2012) Self-Tuning for Job Engagement: Ugandan Nurses' Self-Care Strategies in Coping with Work Stress. International Journal of Mental Health Promotion, 14, 3-12. http://dx.doi.org/10.1080/14623730.2012.682754

[45] Gustafsson, G. and Strandberg, G. (2009) Meanings of Staying Healthy in a Context Where Others Developed Burnout- 
Phenomenological-Hermeneutic Interpretation of Healthcare Personnel's Narratives. Scandinavian Journal of Caring Sciences, 23, 456-464. http://dx.doi.org/10.1111/j.1471-6712.2008.00641.x

[46] Pressman, S.D. and Cohen, S. (2005) Does Positive Affect Influence Health? Psychological Bulletin, 131, 925-971. http://dx.doi.org/10.1037/0033-2909.131.6.925

[47] Steinvil, A., Shirom, A., Melamed, S., Toker, S., Justo, D., Saar, N., et al. (2008) Relation of Educational Level to Inflammation-Sensitive Biomarker Level. American Journal of Cardiology, 102, 1034-1039. http://dx.doi.org/10.1016/j.amjcard.2008.05.055

[48] Antonovsky, A. (1979) Health, Stress, and Coping. Jossey-Bass, San Francisco.

[49] Bandura, A. (1997) Self-Efficacy: The Exercise of Control. Freeman, New York.

[50] Svebak, S. (1997) Does a Good Laughter Prolong Life? Tidsskrift for den Norske Laegeforening, 117, 4360-4361.

[51] Svebak, S. (2005) Does Humor Benefit Health and Well-Being? Tidsskrift for Norsk Psykologforening, 42, 909-912.

[52] Nevo, O., Aharonson, H. and Klingman, A. (1998) The Development and Evaluation of a Systematic Program for Improving Sense of Humor. In: Willibald, R., Ed., The Sense of Humor: Explorations of a Personality Characteristic, Mouton de Gruyter, Berlin, 385-404.

[53] Pask, E.J. (2005) Self-Sacrifice, Self-Transcendence and Nurses' Professional Self. Nursing Philosophy, 6, $247-254$. http://dx.doi.org/10.1111/j.1466-769X.2005.00215.x 